\title{
Pyroelectric properties of ferroelectric potassium-cesium vanadate and potassium-lithium vanadate
}

\author{
A J KULKARNI, A P KASHID ${ }^{+}$and S H CHAVAN ${ }^{\dagger} *$ \\ Walchand Institute of Technology, Solapur 413006 , India \\ + Department of Physics, Warana Mahavidyalaya, Warananagar, Kolhapur 416113, India \\ ${ }^{\dagger}$ Department of Physics, Shivaji University, Kolhapur 416004, India \\ MS received 10 June 1989; revised 23 March 1990
}

\begin{abstract}
Measurements of pyroelectric currents and coefficients of poled sintered discs of ferroelectric solid solutions, potassium-cesium vanadate and potassium-lithium vanadate have been investigated in the temperature range covering their transition points. In these solid solutions, $\mathrm{K}_{x} \mathrm{Cs}_{1-x} \mathrm{VO}_{3}$ and $\mathrm{K}_{x} \mathrm{Li}_{1-x} \mathrm{VO}_{3}$, pronounced peaks have been observed at the ferroelectric curie temperatures. The peak values of pyroelectric currents and coefficients change with change in potassium concentration in both the solid solutions.
\end{abstract}

Keywords. Ferroelectricity: pyroelectricity; phase transition; vanadate solid solutions.

\section{Introduction}

The pyroelectric effect has been known since ancient times. Initially the static method for the measurement of pyroelectric coefficient was introduced by Ackermann (1915). The pyroelectric effect as explained by Cady (1946) is the change in polarization of material when it undergoes a change in its temperature. Chynoweth (1956) devised a dynamic method for the measurement of pyroelectric effect in barium titanate. The direct method for measurement of pyroelectric coefficients of $\mathrm{Sr}_{x} \mathrm{Ba}_{1-x} \mathrm{Nb}_{2} \mathrm{O}_{6}$ was introduced by Byer and Roundy (1972). $\mathrm{Pb}_{3}\left(\mathrm{VO}_{4}\right)_{2}$ crystals were studied for dielectric and pyroelectric measurements in the lowest phase (phase III) by Midorikawa et al (1980). Feigelson et al (1972) have studied structures of single crystalline $\mathrm{LiVO}_{3}$, $\mathrm{NaVO}_{3}$ and $\mathrm{KVO}_{3}$ which were grown from their stoichiometric melts. $\mathrm{LiVO}_{3}$ and $\mathrm{KVO}_{3}$ are found to be monoclinic and orthorhombic respectively. Similar types of investigations have been carried out by Hawthorne and Calvo (1977) on the crystals of $\mathrm{M}^{+} \mathrm{VO}_{3}\left(\mathrm{M}^{+}=\mathrm{Li}, \mathrm{Na}, \mathrm{K}, \mathrm{NH}_{4}, \mathrm{TI}, \mathrm{Rb}\right.$ and $\left.\mathrm{Cs}\right)$. They have reported that the structure of $\mathrm{LiVO}_{3}$ is monoclinic while that of $\mathrm{KVO}_{3}$ and $\mathrm{CsVO}_{3}$ are orthorhombic. Khan et al (1983) studied the dielectric and pyroelectric effect of ferroelectric $\mathrm{NaVO}_{3}$. Patil et al (1988) investigated the properties of ferroelectric $\mathrm{NaVO}_{3}, \mathrm{KVO}_{3}$ and $\mathrm{LiVO}_{3}$ and their solid solutions. The pyroelectric properties of Gd-doped $\mathrm{KVO}_{3}$ and $\mathrm{LiVO}_{3}$ samples have been recently reported by Kashid et al (1989).

The aim of this paper is to report the variations in pyroelectric currents and coefficients with the temperatures in the poled sintered discs of the solid solutions, $\mathrm{K}_{x} \mathrm{Cs}_{1-x} \mathrm{VO}_{3}$ and $\mathrm{K}_{x} \mathrm{Li}_{1-x} \mathrm{VO}_{3}$. These solid solutions being ferroelectric materials exhibit interesting pyroelectric properties and have a practical application as a pyroelectric detector which is of a special interest.

\footnotetext{
*For correspondence.
} 


\section{Experimental}

The stoichiometric mixture of $\mathrm{M}_{2}^{+} \mathrm{CO}_{3}\left(\mathrm{M}^{+}=\mathrm{K}, \mathrm{Cs}\right.$, Li) and $\mathrm{V}_{2} \mathrm{O}_{5}$ was slowly heated at $750^{\circ} \mathrm{C}$ for $4 \mathrm{~h}$ in a platinum crucible inside a globar furnace to form the crystalline solids of potassium vanadate, cesium vanadate and lithium vanadate. Solid solutions, $\mathrm{K}_{x} \mathrm{Cs}_{1-x} \mathrm{VO}_{3}$ were prepared from a mixture of $\mathrm{KVO}_{3}$ and $\mathrm{CsVO}_{3}$ having molar proportions of $x=0.8-0.2$ in the globar furnace at $780^{\circ} \mathrm{C}$ for $4 \mathrm{~h}$ and were allowed to cool to room temperature. Similarly, the solid solutions $\mathrm{K}_{x} \mathrm{Li}_{1-x} \mathrm{VO}_{3}$ $(x=0.8-0.2)$ were prepared. The crystal structures of the samples have been confirmed by X-ray studies. The sintered pellets of the above solid solutions having thicknesses of about $1 \mathrm{~mm}$ and diameters of $1 \mathrm{~cm}$ were placed in a sample holder. The opposite faces of the pellets were coated with thin layers of silver paste for good electrical contact with the electrodes.

The experimental set-up consists of a furnace, electronically regulated power supply to provide a d.c. electric field, a digital d.c. micro-voltmeter (VMV 15), a pico-ammeter adaptor for VMV 15 and a digital multimeter. The test sample was polarized for 10 min at room temperature by a constant d.c. electric field of $250 \mathrm{~V} / \mathrm{cm}$. The test sample electrodes were short circuited for $20 \mathrm{~min}$ to eliminate the current due to the space charge before the pyroelectric measurements were made. This poled sample was slowly heated in a furnace at the rate of about $3^{\circ} \mathrm{C} / \mathrm{min}$ and the pyroelectric current was measured with a digital d.c. micro-voltmeter connected to a pico-ammeter adaptor at various temperatures. The corresponding time was also noted for calculating the rate of heating. The pyroelectric coefficients were calculated by the direct method, as suggested by Byer and Roundy (1972), which is simpler than the dynamic method.

\section{Results and discussion}

Temperature variations of the pyroelectric current deduced by Chynoweth (1956) is given by

$$
i=A\left(\frac{\mathrm{d} p_{s}}{\mathrm{~d} T}\right)\left(\frac{\mathrm{d} T}{\mathrm{~d} t}\right)
$$

where $i$ is the pyroeiectric current, $A$, the area of ceramic material, $p_{s}$ the spontaneous polarization, $\mathrm{d} T / \mathrm{d} t$, the rate of heating and $\mathrm{d} p_{s} / \mathrm{d} T$, the pyroelectric coefficient.

The change of pyroelectric coefficients, calculated by (1) in accordance with the changes in temperatures for ferroelectric solid solutions of $\mathrm{K}_{x} \mathrm{Cs}_{1-x} \mathrm{VO}_{3}$ and $\mathrm{K}_{x} \mathrm{Li}_{1-x} \mathrm{VO}_{3}$ are plotted in figures 1 and 2 and it is clear from the figures that the pyroelectric coefficients show a peak at $405,405,400$ and $400^{\circ} \mathrm{C}$ for different molor proportions of $\mathrm{K}_{x} \mathrm{Cs}_{1-x} \mathrm{VO}_{3}$ and at $350,360,375$ and $375^{\circ} \mathrm{C}$ for different molar proportions of $\mathrm{K}_{x} \mathrm{Li}_{1-x} \mathrm{VO}_{3}$. The above temperatures indicate that the curie temperatures of the respective solid solutions are in good agreement with the values observed by the hysteresis loop method (Sawyer and Tower 1930).

Table 1 summarizes the observations of pyroelectric currents and pyroelectric 


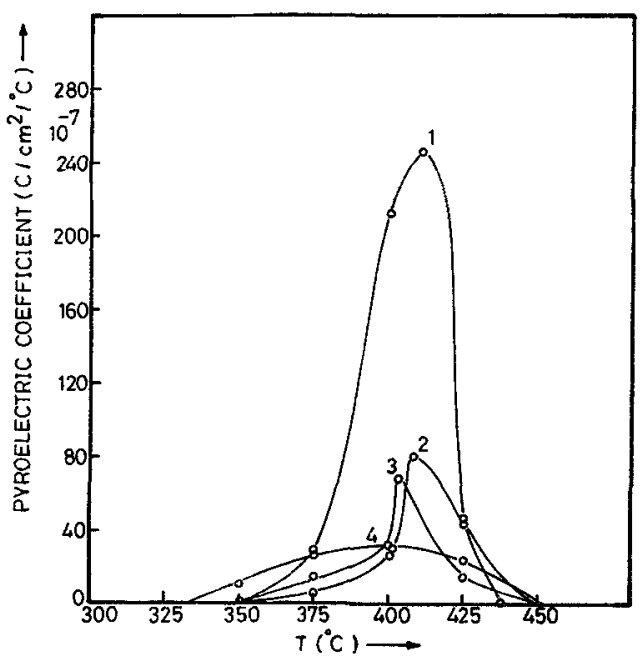

Figure 1. Variation of pyroelectric coefficient with temperature for solid solutions: (1) $\mathrm{K}_{0 \cdot 2} \mathrm{Cs}_{0 \cdot 8} \mathrm{VO}_{3}$, (2) $\mathrm{K}_{0.4} \mathrm{Cs}_{0.6} \mathrm{VO}_{3}$, (3) $\mathrm{K}_{0.6} \mathrm{Cs}_{0 \cdot 4} \mathrm{VO}_{3}$, and (4) $\mathrm{K}_{0.8} \mathrm{Cs}_{0.2} \mathrm{VO}_{3}$.

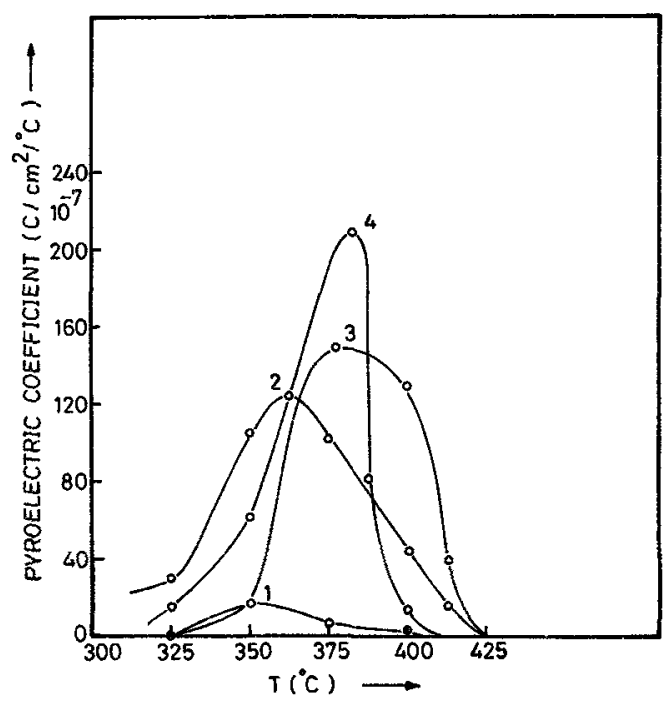

Figure 2. Variation of pyroelectric coefficient with temperature for solid solutions: (1) $\mathrm{K}_{0.2} \mathrm{Li}_{0.8} \mathrm{VO}_{3}(2) \mathrm{K}_{0.4} \mathrm{Li}_{0.6} \mathrm{VO}_{3}$ (3) $\mathrm{K}_{0.6} \mathrm{Li}_{0.4} \mathrm{VO}_{3}$ and (4) $\mathrm{K}_{0.8} \mathrm{Li}_{0.2} \mathrm{VO}_{3}$.

coefficients at the curie temperatures of the vanadates and their solid solutions. The densities for the respective samples have also been mentioned in table 1 .

Table 1 indicates that the pyroelectric current and coefficient decrease as the concentration of $\mathrm{KVO}_{3}$ increases for potassium-cesium vanadate solid solutions and on the other hand, the pyroelectric current and coefficient increase as the concentration of $\mathrm{KVO}_{3}$ increases for potassium-lithium vanadate solid solution. 
Table 1. Peak values of various parameters $\mathrm{KVO}_{3}, \mathrm{CsVO}_{3}, \mathrm{LVO}_{3}$ and their solid solutions.

\begin{tabular}{lcccccc}
\hline & $\begin{array}{c}\text { Pyroelectric } \\
\text { current } \\
\left(10^{-9} \mathrm{~A}\right)\end{array}$ & $\begin{array}{c}\text { Pyroelectric } \\
\text { coefficient } \\
\left(10^{-7} \mathrm{C} / \mathrm{cm}^{\left.2{ }^{\circ} \mathrm{C}\right)}\right.\end{array}$ & $\begin{array}{c}\text { Curie } \\
\text { temp. } \\
\left({ }^{\circ} \mathrm{C}\right)\end{array}$ & $\begin{array}{c}\text { Curie temp. } \\
\text { by hysteresis }\end{array}$ & $\begin{array}{c}\text { Curie temp. by } \\
\text { dielectric const. } \\
\text { measurement }\end{array}$ & $\begin{array}{c}\text { Density } \\
\left(\mathrm{g} / \mathrm{cm}^{3}\right)\end{array}$ \\
\hline $\mathrm{KVO}_{3}$ & $50 \cdot 2$ & $7 \cdot 71$ & 315 & 314 & 315 & $2 \cdot 31$ \\
$\mathrm{CsVO}_{3}$ & 91.4 & $14 \cdot 04$ & 345 & 346 & 347 & $2 \cdot 42$ \\
$\mathrm{LiVO}_{3}$ & 415 & 63.77 & 405 & 405 & 404 & $2 \cdot 24$ \\
$\mathrm{~K}_{2} \mathrm{Cs}_{8} \mathrm{VO}_{3}$ & 1732 & $266 \cdot 17$ & 405 & 406 & 407 & $2 \cdot 33$ \\
$\mathrm{~K}_{4} \mathrm{Cs}_{6} \mathrm{VO}_{3}$ & 522 & $80 \cdot 22$ & 405 & 401 & 402 & $2 \cdot 40$ \\
$\mathrm{~K}_{6} \mathrm{Cs}_{4} \mathrm{VO}_{3}$ & 447 & $68 \cdot 69$ & 400 & 394 & 396 & $2 \cdot 40$ \\
$\mathrm{~K}_{8} \mathrm{Cs}_{2} \mathrm{VO}_{3}$ & 220 & $33 \cdot 80$ & 400 & 391 & 392 & $2 \cdot 42$ \\
$\mathrm{~K}_{2} \mathrm{Li}_{.8} \mathrm{VO}_{3}$ & 100 & $15 \cdot 36$ & 350 & 346 & 345 & $2 \cdot 21$ \\
$\mathrm{~K}_{4} \mathrm{Li}_{.6} \mathrm{VO}_{3}$ & 810 & $124 \cdot 48$ & 360 & 356 & 355 & $2 \cdot 22$ \\
$\mathrm{~K}_{.6} \mathrm{Li}_{.4} \mathrm{VO}_{3}$ & 975 & $149 \cdot 83$ & 375 & 370 & 371 & 2.22 \\
$\mathrm{~K}_{.8} \mathrm{Li}_{.2} \mathrm{VO}_{3}$ & 1348 & $207 \cdot 16$ & 375 & 377 & 376 & $2 \cdot 20$ \\
\hline
\end{tabular}

\section{Conclusions}

(i) The ferroelectric curie temperatures $405,405,400$ and $400^{\circ} \mathrm{C}$ for molar proportions of $\mathrm{K}_{x} \mathrm{Cs}_{1-x} \mathrm{VO}_{3}, x=0 \cdot 2,0 \cdot 4,0 \cdot 6,0 \cdot 8$ and that for $\mathrm{K}_{x} \mathrm{Li}_{1-x} \mathrm{VO}_{3}$ for molar proportions $x=0.2,0.4,0.6,0.8$ are $350,360,375$ and $375^{\circ} \mathrm{C}$ respectively, which are in good agreement with the temperatures investigated by the hysteresis loop method.

(ii) The values of pyroelectric current and coefficient decrease with the increase in proportion of $\mathrm{KVO}_{3}$ in solid solutions $\mathrm{K}_{x} \mathrm{Cs}_{1-x} \mathrm{VO}_{3}$ and these values increase with the increase in proportions of $\mathrm{KVO}_{3}$ in solid solutions $\mathrm{K}_{x} \mathrm{Li}_{1-x} \mathrm{VO}_{3}$.

(iii) These materials can be used as pyroelectric detectors.

\section{References}

Ackermann W 1915 Ann. Phys. 46217

Byer R L and Roundy C B 1972 Ferroelectrics 3333

Cady W G 1946 Piezoelectricity (New York: McGraw Hill)

Chynoweth A G 1956 J. Appl. Phys. 2778

Feigelson R S, Martin G W and Johnson B C 1972 J. Crystal Growth 686

Hawthorne F C and Calvo C 1977 J. Solid State Chem. 22157

Kashid A P, Patil V V and Chavan S H 1989 Bull. Mater. Sci. 1257

Khan A, Ghare D and Narayanan P 1983 Bull. Mater. Sci. 5133

Midorikawa M, Kashid H, Sawada A and Ishibashi Y 1980 J. Phys. Soc. Jpn. 491095

Patil T A, Jamadar V M and Chavan S H 1988 Indian J. Phys. 341

Sawyer C B and Tower C H 1930 Phys. Rev. 35269 